\title{
Self-Reactions of the Public toward People Who Stutter: Age and Sex Differences
}

\author{
HeeCheong Chon \\ Department of Speech-Language Pathology, Chosun University, Gwangju, Korea
}

Correspondence: HeeCheong Chon, $\mathrm{PhD}$ Department of Speech-Language Pathology, Chosun University, 309 Pilmun-daero, Dong-gu, Gwangju 61452, Korea

Tel: +82-62-230-7857

Fax: +82-62-230-6271

E-mail: hchon@chosun.ac.kr

Received: April 5, 2016

Revised: May 19, 2016

Accepted: June 3, 2016

This study was supported by research fund from Chosun University, 2014

\begin{abstract}
Objectives: The purpose of this study was to explore public reactions to people who stutter (PWS) and to assess whether there were any differences in reactions according to sex and age groups. Methods: Participants included 226 normally fluent Korean adults. Their responses on the questionnaire "Self-reactions to PWS," a subcategory of the Public Opinion Survey on Human Attributes-Stuttering (POSHA-S), were analyzed. The four components, 'accommodating/helping,' 'social distance/sympathy,' 'knowledge/experience', and 'knowledge source', were compared among four age groups and sex groups. The self-reactions to PWS score, which is the mean value of the scores of the four components, was also compared. Results: There was no significant interaction or main effect in accommodating/ helping, knowledge/experience, and knowledge source. However, there was a significant interaction effect between age and sex in social distance/sympathy in that the levels of sympathy and impressions regarding PWS worsened with age increments in the male group. The self-reactions to PWS score did not show any significant interaction or main effect. Conclusion: The current findings suggest that regardless of age or sex, public reactions to PWS were not positive. This was due in part to the respondents' lack of knowledge/experience regarding stuttering or PWS, and could potentially influence the ability of PWS to achieve personal and/or professional fulfillment.
\end{abstract}

Keywords: Self-reactions, People who stutter (PWS), Stuttering, POSHA-S, Age, Sex 발달성말더듬(developmental stuttering, 이하 말더듬)은 외현적 으로 관찰되는 핵심행동이나 투쟁행동뿐 아니라 대상자의 내면적 인 특성인 말더듬에 대한 감정, 느낌이나 태도를 장애의 정의에 포 함하고 있으며(Guitar, 2013; Wingate, 1964), 말더듬 진단평가 시 이러한 내면적인 특성을 평가하고 필요한 경우 치료 목표에 반영하 고 있다. 말더듬는 사람에게서 나타나는 말더듬으로 인한 내면적 특성은 개인마다 다양하지만 일반적으로 좌절감, 수치심, 자기비 하, 혹은 부정적인 의사소통태도 및 자아정체감 등 부정적인 경우 가 많고(Manning, 2010), 이로 인해 말더듬는 사람은 타인과 의사 소통을 하거나 관계를 맺고 사회에서 한 개인으로 역할을 수행하 는데 어려움이 발생할 수 있다. Yaruss와 Quesal (2004)은 이를 기 능, 장애, 건강의 국제적 분류(International Classification of Functioning, Disability and Health; World Health Organization, 2001) 의 기준을 적용시켜 '활동/참여의 제한’ 범주에서 설명하였으며, 말
더듬는 사람의 개인적인 요인과 환경적인 요인이 이러한 어려움에 영향을 미친다고 하였다. 개인적 요인은 말더듬는 사람 스스로가 자신의 말에 대해 보이는 반응인 반면 환경적 요인은 말더듬는 사 람이 자신의 말 때문에 경험하게 되는 어려움과 말을 더듬었을 때 일반 청자들이 보이는 반응 등을 의미한다(Chon \& Yaruss, 2015). 즉, 말더듬는 사람 스스로가 느끼는 정서적 반응과 함께 말더듬는 사람이 타인과 의사소통 시 경험하게 되는 다양한 상황이나 사건 들이 말더듬는 사람의 내면적 문제를 야기하거나 심화시킬 수 있으 며, 더 나아가 말더듬는 사람의 개인적, 사회적 성취에 부정적인 영 향을 미칠 수 있음을 알수 있다.

따라서 말더듬는 사람에 대한 일반인의 반응, 고정관념(stereotype: 개인차나 특성, 능력 등을 고려하지 않고 어떠한 집단에 속한 사람들을 단순하게 특정 범주화 시키는 신념) 등과 같은 태도를 살 피는 연구가 다각도로 이루어지고 있다. 일반인이 말더듬는 사람 
에 대해 가지고 있는 태도가 의식적이든 무의식적이든 말더듬는 사 람에게 다양하게 표출될 수 있기 때문이다. 대부분의 선행연구는 일반인이 말더듬는 사람에 대해 부정적인 고정관념이나 태도를 가 지고 있음을 보고하였으며(Boyle, Blood, \& Blood, 2009; Craig, Tran, \& Craig, 2003; de Britto Pereira, Rossi, \& Van Borsel, 2008; Doody, Kalinowski, Armson, \& Stuart, 1993; Sim, 2000) 이러한 경 향은 말더듬 아동의 또래집단을 대상으로 이루어진 연구에서도 동 일하게 나타났다(Evans, Healey, Kawai, \& Rowland, 2008; Langevin, 2009; Langevin, Kleitman, Packman, \& Onslow, 2009; Weidner, St. Louis, Burgess, \& LeMasters, 2015). 최근에는 학령전기 혹은 학령기 말더듬 아동에게 직접적인 영향을 미치는 부모나 교 사를 대상으로 말더듬는 사람에 대한 태도를 살핀 연구가 이루어 지고 있으며, 전반적으로 부모나 교사가 보이는 말더듬는 사람에 대한 고정관념이나 반응 역시 다른 일반인과 큰 차이가 없음을 보 고하고 있다(Al-Khaledi, Lincoln, McCabe, Packman, \& Alshatti, 2009; Arnold, Li, \& Goltl, 2015; Crowe \& Walton, 1981; Dorsey \& Guenther, 2000; Ko, 2015; Lee, 2013; Li \& Arnold, 2015).

말더듬는 사람에 대한 일반인의 태도를 살피기 위해 일반적으로 사용되고 있는 방법은 연구대상자가 말더듬는 사람과 관련된 질문 혹은 서술문을 읽고 리커트 척도나 체크리스트에 답하거나, 단답 형 혹은 서술형으로 답을 작성하는 설문조사법이다(Langevin, 2009; Langevin et al., 2009; Schlagheck, Gabel, \& Hughes, 2009). 하지만 설문도구의 구성이나 내용이 다양하여 연구결과들을 직접 적으로 비교하는 것에 한계가 있었으며, 일반인이 말더듬는 사람 에 대해 가지고 있는 태도의 특정 측면들을 체계적이고 구체적으로 조사하기에는 어려움이 있었다. POSHA-S (Public Opinion Survey on Human Attributes-Stuttering; St. Louis, 2012a)는 말더듬과 관 련된 대중의 태도를 연구하기 위해 개발된 설문도구로 최근 가장 많이 사용되고 있는 설문도구 중 하나이다. 이 설문도구는 1999년 에 개발된 이후 여러 번의 수정절차를 거쳐 완성되었으며 설문도구 의 검사-재검사 신뢰도, 내적일관성 신뢰도, 구성타당도 및 공인타 당도가 입증되었고(St. Louis, 2005, 2012a, 2012b; St. Louis, Lubker, Yaruss, \& Aliveto, 2009; St. Louis, Reichel, Yaruss, \& Lubker, 2009), 2014년 11월 기준으로 37개 국가에서 23개 언어로 번역되어 다양한 국가 및 문화권에서 사용되고 있다(St. Louis, 2014). POSHA$\mathrm{S}$ 는 말더듬는 사람에 대한 응답자의 태도를 체계적이고 구체적으 로 살펴볼 수 있다는 장점이 있다. 이 설문도구는 총 11 개의 구성요 소(component)와 3 개의 하위범주 점수(subscore)로 이루어져 있으 며, 이 중 말더듬 혹은 말더듬는 사람과 관련 있는 구성요소는 '수 용/도움(accommodating/helping)', 사회적 거리/연민(social dis- tance/sympathy)', '지식/경험(knowledge/experience)', '지식의 출 처(knowledge source), '특성/성격(traits/personality)', '도움의 출처 (help source)', '말더듬의 원인(cause)', '가능성(potential)'을 포함한 8 개이다. 구성요소는 서로 연관이 있는 개별 문항들을 범주화한 것 으로 각 구성요소에 속하는 개별문항 점수들의 평균이 그 구성요 소의 점수가 되며, POSHA-S는 각 구성요소를 말더듬는 사람에 대 한 응답자의 태도(attitude)로 설명하고 있다(St. Louis, 2011, 2012b). 하위범주는 서로 관련 있는 구성요소들을 범주화한 것으로 각 하 위범주에 속하는 구성요소 점수들의 평균이 그 하위범주의 점수 가 된다. 말더듬과 관련 있는 하위범주는 '말더듬는 사람에 대한 신 념(beliefs about PWS)'과 '말더듬는 사람에 대한 자기반응(self-reactions to PWS')이다. '말더듬는 사람에 대한 신념'은 말더듬는 사 람에 대한 응답자의 고정관념을 알아보기 위한 하위범주이며, 여기 에 속하는 구성요소('특성/성격', '도움의 출처', '말더듬의 원인', '가 능성')는 응답자가 말더듬이나 말더듬는 사람에 대해 가지고 있는 신념을 측정한다. 반면 '말더듬는 사람에 대한 자기반응은 말더듬 과 관련해서 혹은 말더듬는 사람과 대화를 하거나 자신의 주변사 람이 말을 더듬는 상황에서 응답자 스스로가 어떠한 행동적/정서 적 반응을 보이는지 측정하게 된다. 이 하위범주는 4 개의 구성요 소, 즉 ‘수용/도움, '사회적 거리/연민', ‘지식/경험', ‘지식의 출처'로 이루어져 있다. '수용/도움은 응답자가 말더듬는 사람에게 얼마나 호의적이고 도움이 되는 행동을 하고자 하는지를 측정하며, 사회 적 거리/연민'은 응답자가 말더듬는 사람을 얼마나 친근감 있게 생 각하는가, 말더듬는 사람을 대할 때의 감정이 어떠한가를 측정한 다. 사회적 거리란 개인이나 집단 간 친밀감의 정도를 의미하는 것 으로 개인이 느끼는 심리적인 관계를 나타낸다(Lee, Choi, \& Choi, 2010). POSHA-S는 응답자의 주변인, 예를 들어 자신의 이웃이나 형제자매가 말을 더듬는다면, 그리고 응답자 자신이 말을 더듬는 다면 걱정을 하게 될 것인지 묻고 있으며, 걱정을 할 것이라는 응답 이 많을수록 사회적 거리가 존재함을 나타낸다(Li \& Arnold, 2015). 따라서 ‘사회적 거리/연민' 점수가 낮을수록 사회적 거리가 먼 것이 며, 말더듬는 사람에 대한 응답자의 이해나 친근감이 낮음을 의미 한다. '지식/경험'은 응답자의 경험을 통해 말더듬는 사람에 대해 얼 마나 친숙한지 측정하며, '지식의 출처'는 응답자가 얼마나 다양하 고 많은 수의 자료를 통해 말더듬에 대한 지식이나 정보를 얻었는 지 측정한다. 이 구성요소는 인터넷, 신문, 텔레비전, 학교 등 왜곡 이 있을 수도 있으나 객관적인 지식이나 정보 제공이 가능한 출처 들을 묻는다. 따라서 '말더듬는 사람에 대한 자기반응' 하위범주를 통해 일반인이 보이는 다양한 유형의 자기반응 특성을 구체적으로 살필 수 있으며, 말더듬는 사람에 대한 일반인의 자기반응이 얼마 
나 긍정적인지 혹은 부정적인지를 파악할 수 있다. POSHA-S를 사 용한 선행연구들은 국가나 문화권에 따라 혹은 동일한 국가나 문 화권 내에서도 다양한 결과를 보고하였다. 하지만 전반적으로 '수 용/도움'은 긍정적인 반응을, '사회적 거리/연민'은 중립에 가까운 반응을, '지식/경험'과 '지식의 출처'는 중립이거나 부정적인 반응이 보고되고 있다(Li \& Arnold, 2015; Özdemir, St. Louis, \& Topbaş, 2011; St. Louis, 2012b).

선행연구들은 말더듬는 사람에 대한 일반인의 태도에 영향을 줄 수 있는 인구통계학적 변인(demographic variable)으로 성별, 말 더듬는 사람에 대한 친숙함(familiarity) 여부, 연령, 교육년수 등을 제시하고 있다. 성별에 따른 차이를 살핀 연구들은 성별에 따라 말 더듬는 사람에 대한 태도에 차이가 있었다는 결과(Arnold et al., 2015; de Britto Pereira et al., 2008; Schlagheck et al., 2009)와 성별 에 따른 차이가 없었다는 결과가(Evans et al., 2008; Langevin, 2009; St. Louis, 2012b) 혼재하고 있어 일관된 결론에 이르지 못하고 있 다. 반면 말더듬는 사람에 대한 친숙함 여부를 기준으로 비교하였 을 때, 말더듬는 사람과 친숙한 집단은 그렇지 않은 집단보다 말더 듬는 사람에 대한 고정관념이 적거나 상대적으로 긍정적인 태도를 보이는 것으로 나타났다(Arnold et al., 2015; Klassen, 2002; Langevin, 2009; Langevin et al., 2009; Schlagheck et al., 2009). 연령과 교육년수 역시 말더듬는 사람에 대한 태도나 고정관념 관련 변인 들과 유의한 정적 혹은 부적상관이 있는 것으로 보고되고 있다(AlKhaledi et al., 2009; de Britto Pereira et al., 2008; Li \& Arnold, 2015; St. Louis, Sønsterud, Carlo, Heitmann, \& Kvenseth, 2014). 다양한 인구통계학적 변인에 따른 연구는 말더듬는 사람에 대한 일반인의 태도를 보다 세부적으로 심도 있게 파악할 수 있으며 지역이나 문 화별 특성을 비교할 수 있다는 장점이 있다. 그러나 이러한 변인을 고려한 연구들은 주로 국외에서만 이루어져 왔으며 국내에서는 말 더듬는 사람에 대한 친숙함 여부에 따른 연구가 제한적으로 이루 어지고 있는 상황이다(Han, 2015; Ko, 2015).

본 연구는 일반인이 보이는 말더듬는 사람에 대한 자기반응의 특성을 인구통계학적 변인인 성별과 연령 간 비교하여 보다 심도 있게 살피고자 하는 데 목적이 있었다. 일반인이 말더듬는 사람에 게 어떠한 반응을 보이는지 파악하여야만 말더듬는 사람의 ‘활동/ 참여의 제한'에 직·간접적으로 영향을 주는 환경적 요인을 감소시 킬 수 있는 방법을 모색할 수 있기 때문이다. 이를 위해 응답자의 행 동적/정서적 반응을 각 구성요소를 사용하여 체계적으로 살피고, 점수로 수량화(quantification) 가능하며, 구성요소의 결과를 종합 하여 응답자의 자기반응 특성을 파악할 수 있는 POSHA-S의 '말더 듬는 사람에 대한 자기반응 하위범주를 사용하였다. 구체적인 연
구문제는 다음과 같다.

(1) 연령과 성별에 따라 POSHA-S의 구성요소인 '수용/도움, '사 회적 거리/연민', '지식/경험', '지식의 출처' 점수에 각각 차이가 있는가?

(2) 연령과 성별에 따라 POSHA-S의 하위범주인 '말더듬는 사람 에 대한 자기반응 점수에 차이가 있는가?

\section{연구 방법}

\section{연구대상}

연구대상은 만 19세 이상의 성인남녀로 연구참여에 대한 설명을 듣고 이에 동의한 불특정 일반인이었다. 또한 대상자 본인의 보고 를 통해 (1) 대한민국에 거주하고 있으며, (2) 한국어를 모국어로 사 용하고 있고, (3) 언어병리학 및 유창성장애 관련 전공지식을 습득 한 경험이 없고, (4) 시각 및 청각에 문제가 없으며, (5) 읽기 이해에 문제가 없는 경우 본 연구 대상에 포함시켰다.

POSHA-S는 25-50명 정도의 표본크기로도 "만족스러운(satisfactory)” 결과를 얻을 수 있으므로(St. Louis, 2012a) 연령집단별 최 소 50명 이상을 대상으로 자료를 수집하였으며 각 연령집단 내 성 비를 최대한 맞추었다. '말더듬는 사람에 대한 자기반응' 하위범주 의 문항에 응답한 총 231 명의 대상자 중 성실하게 응답하지 않았던 5 명을 제외한 226명이 최종적으로 연구대상으로 선정되었다. 연령 과 성별에 따른 대상자의 정보는 Table 1 에 제시하였다. 20 대 집단 은 만 19세-29세의 성인 66명(남성 27명)으로 대상자의 평균연령은 23.70세 $(\mathrm{SD}=2.39)$ 였다. 30 대 집단은 53명(남성 25명)으로 대상자 의 평균연령은 34.00 세 $(\mathrm{SD}=2.65)$ 였으며, 40 대 집단은 53 명(남성 24 명)으로 대상자의 평균연령은 44.77 세 $(\mathrm{SD}=2.82)$ 였다. 마지막으 로 50대 이상 집단은 54 명(남성 25 명)이었으며 대상자의 평균연령 은 54.54세 $(\mathrm{SD}=3.71)$ 였다. 카이제곱검정 결과, 연령집단 간 남성집 단과 여성집단의 표본크기에는 유의한 차이가 없었다 $\left(\chi^{2}(3)=.58\right.$, $p>.05)$. 대상자의 교육년수와 경제적 수준은 대상자가 POSHA-S 의 기본배경정보, 즉, 생활연령, 성별, 교육년수, 경제적 수준과 관련 된 질문에 답한 내용을 바탕으로 측정하였다. 경제적 수준은 대상 자가 가족의 연 소득 정도에 대한 두 개 문항에 리커트 척도(1: 가장 낮음, 2: 낮음, 3: 보통, 4: 높음, 5: 가장 높음)로 응답한 내용을 POSHA-S의 자료분석방법과 동일하게 최저 - 100 점(가장 낮음)에서 최고 +100 점(가장 높음)으로 변환하여 산출하였다. 연령과 성별 요 인 간 교육년수와 경제적 수준을 각각 비교한 결과, 경제적 수준은 유의한 상호작용 및 주효과가 없는 것으로 나타났다. 교육년수는 연령과 성별 간 상호작용은 없었으나 연령에 유의한 주효과가 있었 
Table 1. Participants' information

\begin{tabular}{|c|c|c|c|c|c|}
\hline Age group (yr) & Sex & No. of participants (\%) & Age (yr) & Education (yr) & Income rating \\
\hline $19-29$ & $\begin{array}{l}\text { Male } \\
\text { Female } \\
\text { Total }\end{array}$ & $\begin{array}{l}27(40.91) \\
39(59.09) \\
66(100)\end{array}$ & $\begin{array}{l}24.65 \pm 2.27 \\
23.04 \pm 2.26 \\
23.70 \pm 2.39\end{array}$ & $\begin{array}{l}14.81 \pm 1.69 \\
15.23 \pm 1.63 \\
15.06 \pm 1.65\end{array}$ & $\begin{array}{l}-9.26 \pm 23.27 \\
-4.49 \pm 22.61 \\
-6.44 \pm 22.82\end{array}$ \\
\hline $30-39$ & $\begin{array}{l}\text { Male } \\
\text { Female } \\
\text { Total }\end{array}$ & $\begin{array}{l}25(47.17) \\
28(52.83) \\
53(100)\end{array}$ & $\begin{array}{l}34.77 \pm 2.59 \\
33.32 \pm 2.56 \\
34.00 \pm 2.65\end{array}$ & $\begin{array}{l}15.84 \pm 1.14 \\
15.36 \pm 2.56 \\
15.58 \pm 2.01\end{array}$ & $\begin{array}{l}7.19 \pm 34.07 \\
1.48 \pm 39.10 \\
4.20 \pm 36.47\end{array}$ \\
\hline $40-49$ & $\begin{array}{l}\text { Male } \\
\text { Female } \\
\text { Total }\end{array}$ & $\begin{array}{l}24(45.28) \\
29(54.72) \\
53(100)\end{array}$ & $\begin{array}{l}44.43 \pm 2.83 \\
45.05 \pm 2.83 \\
44.77 \pm 2.82\end{array}$ & $\begin{array}{l}16.04 \pm 2.29 \\
14.76 \pm 2.17 \\
15.34 \pm 2.30\end{array}$ & $\begin{array}{r}5.09 \pm 33.31 \\
.26 \pm 29.44 \\
2.48 \pm 31.05\end{array}$ \\
\hline$>50$ & $\begin{array}{l}\text { Male } \\
\text { Female } \\
\text { Total }\end{array}$ & $\begin{array}{l}25(46.30) \\
29(53.70) \\
54(100)\end{array}$ & $\begin{array}{l}54.78 \pm 4.01 \\
54.33 \pm 3.48 \\
54.54 \pm 3.71\end{array}$ & $\begin{array}{l}14.48 \pm 2.90 \\
13.97 \pm 3.17 \\
14.20 \pm 3.03\end{array}$ & $\begin{array}{l}-6.63 \pm 29.66 \\
-8.00 \pm 39.83 \\
-7.35 \pm 35.07\end{array}$ \\
\hline Total & $\begin{array}{l}\text { Male } \\
\text { Female } \\
\text { Total }\end{array}$ & $\begin{array}{l}101(44.69) \\
125(55.31) \\
226(100)\end{array}$ & $\begin{array}{l}39.31 \pm 11.75 \\
37.71 \pm 12.52 \\
38.43 \pm 12.18\end{array}$ & $\begin{array}{l}15.28 \pm 2.17 \\
14.86 \pm 2.42 \\
15.04 \pm 2.32\end{array}$ & $\begin{array}{l}-1.48 \pm 30.38 \\
-3.02 \pm 32.08 \\
-2.33 \pm 31.26\end{array}$ \\
\hline
\end{tabular}

Values are presented as number $(\%)$ or mean \pm SD.

aRanged from -100 (the lowest) to +100 (the highest).

으며 $\left(F_{(3,218)}=3.84, p<.05\right)$, 사후검정 결과 50 대 집단이 30 대 집단 $(p<.05)$ 과 40 대 집단 $(p<.05)$ 보다 평균 교육년수가 유의하게 낮은 것으로 나타났다.

\section{연구절차}

\section{검사도구}

말더듬는 사람에 대한 일반인의 자기반응을 측정하기 위해 $\mathrm{PO}-$ SHA-S (St. Louis, 2012a)를 한국어로 번역하여 사용하였다. POSHA-S를 사용하기 위하여 이 설문지의 저작권자인 Kenneth St. Louis에게 연구목적의 사용승인을 받았다. 그 후 영문으로 되어있 는 설문지를 2 급 언어재활사 자격증을 소지하고 있으며 유창성장 애 관련 주제로 석사학위 논문을 쓰는 언어병리학 대학원생이 한 국어로 번역하고, 이 연구의 저자가 내용상 오류나 왜곡이 있는지, 한국어 사용자가 읽고 답하기에 어색하거나 해석상 문제가 있는지 여부를 확인하여 수정하는 절차를 진행하였다. 그 후 한국어-영어 이중언어 사용자가 한국어로 번역한 설문지를 영어로 역번역하였 다. 영어로 역번역한 설문지는 저작권자가 직접 원 설문지의 내용 과 비교하여 의미상 왜곡이나 오류가 있는지 여부를 확인한 후 최 종적으로 한국어 POSHA-S 번역본을 완성하였다.

POSHA-S의 하위범주인 '말더듬는 사람에 대한 자기반응'을 측 정하는 문항은 총 23 개이다. 이 하위범주를 구성하는 4 개 구성요 소 중 ‘수용/도움은 6 개의 문항으로 이루어져 있으며, 말을 더듬는 사람과 대화할 때 자신이 어떻게 반응할 것인지(예시문항: 말을 더 듬는 사람과 대화할 때 그 사람에게 천천히 말하거나 긴장을 풀라 고 말할 것이다), 자신이 말더듬는 사람을 도울 수 있다고 생각하는
지 등을 '그렇다/아니다/잘 모르겠음'으로 답하게 하고 있다. '사회 적 거리/연민'은 9 개의 문항으로 구성되어 있다. 말더듬는 사람과 대화할 때 자신의 감정이 어떨지(예시문항: 말을 더듬는 사람과 대 화할 때 그 사람을 불쌍히 여길 것이다), 주변에 말을 더듬는 사람 이 있다면 걱정스러울지 여부(예시문항: 나의 형제/자매가 말을 더 듬는다면 걱정하게 될 것이다)를 '그렇다/아니다/잘 모르겠음'으로 답하게 한다. 또한 말더듬는 사람에 대한 전반적인 인상이 어떤지, 자신이 말더듬는 사람이 되고 싶은지에 대한 질문에 각각 5 점 척도 (매우 부정적임-매우 긍정적임; 매우 동의하지 않음-매우 동의함) 로 대답하게 되어있다. '지식/경험'은 말더듬는 사람에 대한 친숙성 을 알아보기 위한 3 개의 문항으로 이루어져 있으며, 말더듬는 사람 에 대해 알고 있는 정도를 5점 척도(없음-매우 많이)로 답하고, 말 더듬에 대한 지식이 개인적인 경험에서 왔는지에 대해 '그렇다/아니 다/잘 모르겠음으로 답하게 되어 있다. 또한 말더듬는 사람과 개인 적인 친분이 있는지에 답한다. 마지막으로 '지식의 출처'는 총 5 문항 으로 자신의 말더듬에 대한 지식이 개인적인 경험 외에 어디에서 왔는지(예: 텔레비전, 신문, 인터넷 등)에 대해 '그렇다/아니다/잘 모 르겠음으로 답하게 되어 있다.

\section{자료수집}

자료수집은 이 연구의 저자와 언어재활사 2 급자격증을 소지하 고 있으며 유창성장애 관련 주제로 학위논문을 쓰고 있는 언어병 리학 석사과정 학생 두 명에 의해 이루어졌다. 학생들은 저자로부 터 이 연구의 목적과 POSHA-S 작성방법 등에 대한 설명을 들은 후 자료를 수집하였다. 자료수집은 연구대상자에게 이 연구의 목적 
Table 2. Results of correlation analysis between dependent variables and covariate

\begin{tabular}{lccccc}
\hline & Accommodating/helping & Social distance/sympathy & Knowledge/experience & Knowledge source & Self-reactions to PWS \\
\hline Years of education & .107 & .038 & .060 & $.154^{*}$ & $.181^{* *}$ \\
Accommodating/helping & - & .115 & .098 & -.029 & $.447^{* *}$ \\
Social distance/sympathy & - & - & .066 & .040 & $.499^{* *}$ \\
Knowledge/experience & - & - & - & -.042 & $.502^{* *}$ \\
Knowledge source & - & - & - & - & $.625^{* *}$ \\
\hline
\end{tabular}

PWS = people who stutter.

${ }^{*} p<.05,{ }^{* *} p<.01$.

과 절차를 설명하고 연구참여에 대한 동의를 얻은 후 이루어졌다. 연구대상자 선정기준을 만족하는지 확인하기 위하여 연구대상자 는 선정기준 관련 문항에 답하는 질문지를 작성하였으며, 그 후 POSHA-S의 '말더듬는 사람에 대한 자기반응' 범주의 문항에 답 하였다.

\section{자료분석}

말더듬는 사람에 대한 일반인의 자기반응을 측정하기 위해 대상 자가 응답한 각 문항은 St. Louis (2012a, 2012b)의 방법을 따라 모두 -100 점에서 +100 점으로 변환하여 분석하였다. 변환 방법은 다음과 같다: (1) 1 점-5점 척도로 답한 문항의 경우, $1=-100$ 점, $2=-50$ 점, 3 (보통/중립) $=0$ 점, $4=+50$ 점, $5=+100$ 점으로 변환하였다. (2) -2점 에서 +2 점 척도로 답하는 문항의 경우, $-2=1,-1=2,0=3,+1=4$, $+2=5$ 로 우선 변환한 후, (1)번의 분석방식을 따랐다. (3) '그렇다/아 니다/잘 모르겠음으로 답한 문항들은 아니다 $=1$, 잘 모르겠음 $=2$, 그렇다 $=3$ 으로 우선 변환한 후 $1=-100$ 점, $2=0$ 점, $3=+100$ 점으로 변환하였다. 역변환시켜야 하는 10 개 문항의 경우, 기본적인 점수 변환 방식과 반대로 변환하였다. 각 문항에 대한 응답을 점수로 변 환한 후, 4 개 구성요소의 점수를 얻기 위해 각 구성요소 내 문항들 의 평균점수를 계산하였다. 또한 4 개 구성요소 점수들의 평균을 계 산하여 최종적으로 '말더듬는 사람에 대한 자기반응' 점수를 산출 하였다.

POSHA-S에서 최저점인 -100점은 문항에 부정적으로 응답했거 나 말더듬 혹은 말더듬는 사람과 관련된 인식이나 정보가 낮거나 없음을 의미한다. 반대로 최고점인 +100 점은 문항에 긍정적으로 응답했거나말더듬 혹은 말더듬는 사람과 관련된 인식이나 정보가 높거나 많음을 의미한다. 따라서 점수가 +100 에 가까울수록 응답 자의 의견이 긍정적임을 의미한다.

\section{자료의 통계적 처리}

모든 자료의 통계적 분석은 IBM SPSS Statistics ver. 21을 사용하 였다. 본 연구에서는 말더듬는 사람에게 보이는 일반성인의 자기반
응을 확인하기 위해 연령(4개 집단)과 성별(2개 집단)을 독립변수 로 설정하였으며, 4 개 구성요소인 '수용/도움, '사회적 거리/연민', '지식/경험', '지식의 출처' 점수와 최종 점수인 '말더듬는 사람에 대 한 자기반응 점수를 종속변수로 설정하였다. 종속변수들 간 상관 을 확인하기 위하여 피어슨 적률상관계수(Pearson's product moment correlation coefficient)를 사용한 상관분석을 실시한 결과, 구성요소들 간 유의한 상관관계가 나타나지 않았으며 상관 정도도 매우 낮게 나타났다(Table 2). '말더듬는 사람에 대한 자기반응' 점 수의 경우 모든 구성요소와 유의한 정적상관을 보였다. 이는 '말더 듬는 사람에 대한 자기반응 점수가 구성요소 점수의 평균 값이기 때문으로 해석할 수 있다. 또한 연령과 성별 외에 일반인의 자기반 응에 영향을 미칠 수 있는 잠재적 요인인 교육년수와 종속변수 간 상관이 있는지 분석한 결과, 교육년수는 '지식의 출처' 점수와 '말더 듬는 사람에 대한 자기반응 점수와 유의한 정적상관을 나타냈다.

따라서 연령 간 유의한 차이가 있었고 종속변수와 유의한 상관 을 보인 교육년수를 공변량으로 통제하고, 연령과 성별에 따른 구 성요소('수용/도움, '사회적 거리/연민', '지식/경험', '지식의 출처') 점수에 차이가 있는지 확인하기 위하여 공분산분석(ANCOVA)을 각각 실시하였으며, 요인 간 유의한 상호작용이 나타난 경우 추가 적으로 공분산분석을 실시하고 사후검정을 실시하였다. '말더듬 는 사람에 대한 자기반응’ 점수 역시 동일하게 공분산분석을 실시 하였다.

\section{연구 결과}

연령과 성별에 따른 구성요소 점수의 기술통계 결과는 Table 3에 제시하였으며 평균 값은 공변량인 교육년수를 통제한 값으로 제시 하였다. ‘수용/도움'의 경우 모든 집단의 평균이 양수(+)였으며, 남 성집단이 여성집단에 비해 전반적인 평균점수가 상대적으로 높게 나타났으나 20 대 집단의 경우 여성집단의 평균점수가 높게 나타났 다. '사회적 거리/연민'의 평균점수는 모두 음수(-)였으며, 20대 집단 과 30 대 집단은 여성집단의 평균점수가 남성집단에 비해 낮게 나왔 
Table 3. Descriptive statistics of dependent variables according to age and sex groups

\begin{tabular}{|c|c|c|c|c|c|c|}
\hline \multirow{2}{*}{ Dependent variables } & \multirow{2}{*}{ Sex } & \multirow{2}{*}{ Age group (yr) } & \multirow{2}{*}{ Adjusted mean } & \multirow{2}{*}{ Standard error } & \multicolumn{2}{|c|}{$95 \%$ confidence interval } \\
\hline & & & & & Lower bound & Upper bound \\
\hline \multirow[t]{8}{*}{ Accommodating/helping } & Male & $19-29$ & 7.71 & 6.24 & -4.60 & 20.01 \\
\hline & & $30-39$ & 19.01 & 6.53 & 6.14 & 31.88 \\
\hline & & $40-49$ & 20.25 & 6.69 & 7.07 & 33.43 \\
\hline & & $>50$ & 18.01 & 6.51 & 5.19 & 30.84 \\
\hline & Female & $19-29$ & 24.54 & 5.20 & 14.31 & 34.78 \\
\hline & & $30-39$ & 16.74 & 6.14 & 4.65 & 28.83 \\
\hline & & $40-49$ & 13.54 & 6.03 & 1.66 & 25.42 \\
\hline & & $>50$ & 16.99 & 6.11 & 4.94 & 29.03 \\
\hline \multirow[t]{8}{*}{ Social distance/sympathy } & Male & $19-29$ & -7.50 & 6.50 & -20.31 & 5.31 \\
\hline & & $30-39$ & -13.46 & 6.80 & -26.85 & -0.07 \\
\hline & & $40-49$ & -32.24 & 6.96 & -45.96 & -18.52 \\
\hline & & $>50$ & -30.33 & 6.77 & -43.68 & -16.99 \\
\hline & Female & $19-29$ & -25.37 & 5.41 & -36.02 & -14.71 \\
\hline & & $30-39$ & -40.15 & 6.38 & -52.74 & -27.57 \\
\hline & & $40-49$ & -20.28 & 6.27 & -32.64 & -7.92 \\
\hline & & $>50$ & -20.00 & 6.36 & -32.54 & -7.47 \\
\hline \multirow[t]{8}{*}{ Knowledge/experience } & Male & $19-29$ & -54.10 & 7.79 & -69.45 & -38.75 \\
\hline & & $30-39$ & -44.00 & 8.15 & -60.05 & -27.95 \\
\hline & & $40-49$ & -44.91 & 8.34 & -61.36 & -28.47 \\
\hline & & $>50$ & -47.94 & 8.12 & -63.94 & -31.94 \\
\hline & Female & $19-29$ & -68.30 & 6.48 & -81.07 & -55.53 \\
\hline & & $30-39$ & -53.23 & 7.65 & -68.31 & -38.15 \\
\hline & & $40-49$ & -50.62 & 7.52 & -65.44 & -35.81 \\
\hline & & $>50$ & -51.14 & 7.62 & -66.16 & -36.12 \\
\hline \multirow[t]{8}{*}{ Knowledge source } & Male & $19-29$ & -6.46 & 10.57 & -27.29 & 14.38 \\
\hline & & $30-39$ & -3.30 & 11.06 & -25.09 & 18.50 \\
\hline & & $40-49$ & -19.96 & 11.33 & -42.29 & 2.36 \\
\hline & & $>50$ & -6.46 & 11.02 & -28.18 & 15.25 \\
\hline & Female & $19-29$ & 3.33 & 8.80 & -14.01 & 20.67 \\
\hline & & $30-39$ & -5.58 & 10.39 & -26.06 & 14.89 \\
\hline & & $40-49$ & -22.27 & 10.21 & -42.38 & -2.15 \\
\hline & & $>50$ & 9.30 & 10.35 & -11.10 & 29.69 \\
\hline \multirow[t]{8}{*}{ Self-reactions to PWS } & Male & $19-29$ & -15.09 & 4.13 & -23.24 & -6.95 \\
\hline & & $30-39$ & -10.47 & 4.32 & -18.99 & -1.95 \\
\hline & & $40-49$ & -19.21 & 4.43 & -27.93 & -10.48 \\
\hline & & $>50$ & -16.67 & 4.31 & -25.16 & -8.18 \\
\hline & Female & $19-29$ & -16.45 & 3.44 & -23.22 & -9.67 \\
\hline & & $30-39$ & -20.60 & 4.06 & -28.60 & -12.60 \\
\hline & & $40-49$ & -19.90 & 3.99 & -27.76 & -12.04 \\
\hline & & $>50$ & -11.23 & 4.04 & -19.21 & -3.26 \\
\hline
\end{tabular}

으나 40 대 집단과 50 대 이상 집단의 경우 그 반대로 여성집단의 평 균점수가 높은 것으로 나타났다. '지식/경험'은 모든 집단의 평균이 음수(-)였으며 다른 구성요소 점수들과 비교했을 때 상대적으로 더 낮은 평균점수를 보였다. 또한 모든 연령에서 여성집단이 남성집단 보다 상대적으로 더 낮은 평균 점수를 보였다. '지식의 출처'의 경우, 연령과 성별에 따른 차이가 다양하게 나타났으나 40 대 집단이 다 른 연령집단에 비해 공통되게 낮은 점수를 보였다.

각 구성요소의 연령과 성별요인 간 평균점수 차이가 유의했었는
지 알아보기 위하여 ANCOVA를 각각 실시하였다. 그 결과, ‘수용/ 도움 점수는 요인간 유의한 상호작용이 나타나지 않았으며 $\left(F_{(3,217)}=\right.$ $1.52, p>.05)$, 각 요인의 주효과 역시 유의하지 않았다(성별 $F_{(1,217)}=$ $.15, p>.05$; 연령 $\left.F_{(3,217)}=.03, p>.05\right)$. '지식/경험' 점수도 유의한 상 호작용 $\left(F_{(3,217)}=.20, p>.05\right)$ 이나 주효과가 나타나지 않았으며(성별 $F_{(1,217)}=2.19, p>.05 ;$ 연령 $\left.F_{(3,217)}=1.48, p>.05\right)$, '지식의 출처' 점수 도 마찬가지로 상호작용 $\left(F_{(3,217)}=.36, p>.05\right)$ 과 주효과가 유의하지 않았다 (성별 $F_{(1,217)}=.50, p>.05$; 연령 $F_{(3,217)}=1.78, p>.05$ ). 하지만 


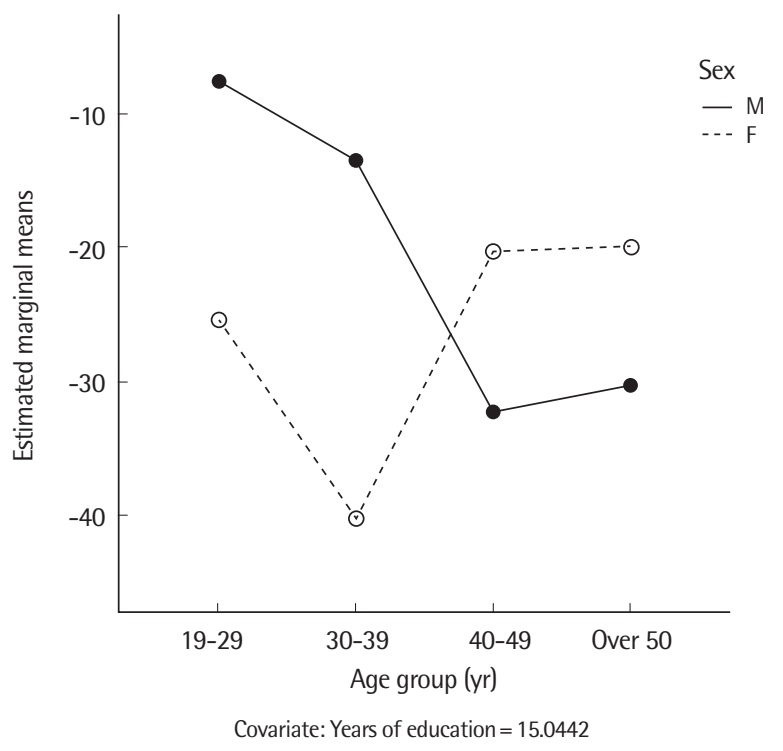

Figure 1. Interaction between age and sex: social distance/sympathy.

‘사회적 거리/연민' 점수의 경우 요인 간 유의한 상호작용 효과가 나 타났다 $\left(F_{(3,217)}=4.57, p<.01\right.$, partial $\left.\eta^{2}=.06\right)$. Figure 1은 '사회적 거 리/연민' 구성요소에서 나타난 상호작용 그래프이다. 20대 집단과 30 대 집단의 경우, 남성집단이 여성집단보다 수정된 평균점수가 더 높았으나 40대 집단과 50대 이상 집단에서는 반대로 여성집단이 남성집단보다 수정된 평균점수가 더 높았음을 알 수 있었다. 따라 서 남성집단과 여성집단 각각에서 연령에 따른 '사회적 거리/연민' 점수에 차이가 있는지 확인하기 위한 추가 분석을 실시하였다. 남 성집단을 대상으로 $\mathrm{ANCOVA}$ 를 실시한 결과, 연령 간 사회적 거리/ 연민' 점수가 동일하지 않은 것으로 나타났다 $\left(F_{(3,96)}=3.32, p<.05\right.$, $\left.\operatorname{partial} \eta^{2}=.09\right)$. 사후검정 결과, 20 대 집단이 40 대 집단 $(p<.05)$ 과 50 대 이상 집단 $(p<.05)$ 보다 평균점수가 유의하게 높은 것으로 나 타났다. 반면 여성집단의 경우, 연령간 점수에 유의한 차이가 없는 것으로 나타났다 $\left(F_{(3,120)}=2.15, p>.05\right)$.

4 개 구성요소의 평균을 계산하여 얻은 최종점수인 '말더듬는 사람에 대한 자기반응' 점수의 기술통계 결과는 Table 3의 하단에 제시하였다. 평균점수는 연령과 성별에 상관없이 모두 음수(-)로 나 타나 일반인이 말더듬는 사람에게 보이는 자기반응이 부정적인 것 으로 나타났다. 그중 30대 집단은 여성집단의 평균점수가 상대적 으로 낮았으며 50대 이상 집단은 남성집단의 평균점수가 상대적으 로 낮은 것으로 나타났다. 그러나 ANCOVA 실시 결과, 요인 간 상 호작용효과는 유의하지 않았으며, 연령요인의 주효과와 성별요인 의 주효과 역시 유의하지 않은 것으로 나타났다(Table 4).
Table 4. Results of ANCOVA for the self-reactions to PWS

\begin{tabular}{lrrcc}
\hline & \multicolumn{1}{c}{ SS } & \multicolumn{1}{c}{ df } & \multicolumn{1}{c}{$F$} & Partial $\eta^{2}$ \\
\hline Years of education (covariate) & $3,609.46$ & 1 & $7.84^{* *}$ & .035 \\
Sex & 155.68 & 1 & .34 & .002 \\
Group & 880.62 & 3 & .64 & .009 \\
Sex×Group & $1,636.08$ & 3 & 1.18 & .016 \\
Errors & $99,923.44$ & 217 & - & - \\
\hline
\end{tabular}

PWS = people who stutter.

${ }^{* *} p<.01$.

\section{논의 및 결론}

본 연구는 말더듬는 사람에게 보이는 일반인의 자기반응 특성 을 알아보기 위하여 인구통계학적 변인인 연령과 성별에 따른 차이 를 교육년수를 통제하고 비교하였다. 연구 결과, (1) '말더듬는 사람 에 대한 자기반응'의 구성요소인 '수용/도움' '지식/경험', '지식의 출처'의 연령과 성별에 따른 평균점수는 유의한 차이가 없었다. '사 회적 거리/연민'의 경우, 남성집단은 20 대 집단이 40 대 집단과 50 대 이상 집단보다 유의하게 높은 평균점수를 보였으나 여성집단은 연 령 간 평균점수에 유의한 차이가 없었다. (2) '말더듬는 사람에 대 한 자기반응 평균점수는 연령과 성별에 따른 유의한 차이가 나타 나지 않았다.

교육년수를 통제한 후 4 개 구성요소 각각을 살폈을 때 '수용/도 움, '지식/경험', '지식의 출처'에서 연령과 성별에 따른 차이가 나타 나지 않았던 결과는 이와 관련된 일반인의 자기반응이 비슷했음을 의미한다. 서론에서 언급하였듯이 '수용/도움'은 응답자가 말더듬 는 사람에게 호의적이고 자신이 도움을 주고자 하는지를 측정한 다. 따라서 이 구성요소의 점수가 연령과 성별에 상관없이 모두 양 수였다는 것은 일반인이 말더듬는 사람에 대해 수용적이고 도움 을 주려 하는 긍정적 반응을 보이고 있음을 시사한다. 그러나 모든 집단의 평균점수는 최대 25점 미만으로 국외에서 이루어진 선행연 구들의 결과와 비교했을 때 상대적으로 낮게 나타났다. $\mathrm{Li}$ 와 $\mathrm{Ar}-$ nold (2015)는 일반인의 '수용/도움' 평균점수가 남성집단은 49.28 점, 여성집단은 55.59점이었다고 보고하였으며, St. Louis (2012b) 역 시 남성집단은 45 점, 여성집단은 54점이었다고 보고하였다. 두 선행 연구는 모두 POSHA-S자료를 관리하는 International Project on Attitudes Toward Human Attributes (IPATHA)의 데이터베이스 에서 응답자료를 선정하였지만 $\mathrm{Li}$ 와 Arnold (2015)는 미국인의 자 료만을 사용하였으며 St. Louis (2012b)는 13개 국가에서 얻어진 자 료 중 100 명의 응답자료를 무작위로 선정하였기 때문에 동일한 자 료에서 얻어진 결과로 보기보다는 각각의 결과로 해석해야 할 것으 
로 보인다. 이러한 평균점수의 차이는 부분적으로 국내 일반인이 말더듬는 사람에게 적절한 도움을 주는 방법을 알지 못하기 때문 일 수도 있다. 예를 들어, 이 구성요소에 속하는 문항 중 “말을 더듬 는 사람과 대화할 때 그 사람에게 천천히 말하거나 긴장을 풀라고 말할 것이다”라는 문항은 총 226 명의 응답자 중 ‘그렇다'고 한 응답 자가 175명(77.4\%)으로 '잘 모르겠음'(11명, 4.9\%)과 '아니다’(40명, $17.7 \%)$ 라는 응답에 비해 압도적으로 높았음을 확인할 수 있었다. 이는 말더듬이라는 장애에 대한 이해가 부족하기 때문으로 보이 며, 도움을 주려는 일반인의 반응 혹은 시도가 말더듬는 사람에게 는 부정적인 영향을 미치는 결과를 초래할 수 있을 것으로 보인다.

일반인이 말더듬는 사람에 대해 얼마나 친숙함을 가지고 있는지 확인하는 '지식/경험'의 경우, 모든 집단의 점수가 -50점에 가까웠 으며 이는 다른 구성요소 점수들보다도 낮은 점수였다. 이러한 결 과는 다른 구성요소들보다 낮은 점수를 보였던 선행연구와 동일한 결과이다(Li \& Arnold, 2015; St. Louis, 2012b). 말더듬는 사람에게 친숙함을 보이지 못했던 결과는 일반인이 말더듬는 사람과 대면하 거나 의사소통을 하는 기회가 적기 때문에 말더듬에 대해 잘 알지 못하고, 따라서 말더듬는 사람에 대한 관심이 낮았기 때문일 수 있 다. 혹은 말더듬의 정의를 알지 못하기 때문에 말더듬는 사람과 대 면하더라도 그들의 비정상적 비유창성을 인지하지 못하였을 수도 있다. '지식의 출처'의 평균점수 역시 대부분 음수이거나 중립점수 에 가까웠던 이번 연구결과는 일반인이 말더듬는 사람에 대해 알 기 위해 말더듬 관련 정보를 찾아보고자 하는 시도가 적었음을 의 미한다. 하지만 이 결과는 일반인이 말더듬에 관심을 갖고 관련정 보를 찾아보고자 할지라도 말더듬에 대한 객관적인 정보를 얻을 수 있는 출처가 다양하지 못하거나 제한되어 있음을 시사한다. 따 라서 일반인에게 말더듬이라는 장애에 대해 알려주고 말더듬는 사 람을 적절히 도울 수 있는 방법을 알려주기 위한 실제적인 자료의 개발이 필요하며, 이러한 자료들이 다양한 방법으로 제시되고 사 용될 수 있어야 할 것으로 보인다.

연령과 성별에 따른 유의한 상호작용효과를 보였던 사회적 거 리/연민'의 경우, 40 대 이상 높은 연령대의 남성집단이 20 대 남성집 단보다 말더듬는 사람에 대한 이해 정도나 친근감이 낮았음을 알 수 있었다. 선행연구에서는 연령별 비교가 이루어지지 않았기 때문 에 본 연구결과와의 직접적인 비교는 어렵지만, 연령을 공변량으로 통제한 Li와 Arnold (2015)는 성별에 따른 유의한 차이가 없었음을 보고하였다. 이와 관련하여 이 구성요소에 속하는 문항들을 확인 해본 결과 40 대 이상의 남성집단은 말더듬는 사람과 이야기할 때 편안함을 느끼는지에 대한 응답이 20대 집단보다 상대적으로 부정 적이었다. 또한 자신의 주변 사람이 말을 더듬을 경우 걱정이 될 것
인지에 대한 문항에서 40 대 이상 집단은 걱정이 될 것이라는 반응 이 높아 사회적인 거리가 멀게 나타났다. 이러한 각 문항에서의 응 답 경향으로 인해 남성집단의 사회적 거리/연민'의 점수가 연령이 증가할수록 낮아진 것으로 보인다. 여성집단의 경우 각 문항에 따 른 개인차를 보이기도 하였으나 그러한 영향이 구성요소 점수에는 반영되지 않은 것으로 보인다. 높은 연령대에서 남성집단의 점수가 낮았던 결과는 Hurst와 Cooper (1983)의 결과와 맥락을 같이한다. 고용주들의 말더듬에 대한 인식을 조사한 이 연구는 말더듬이 고 용가능성이나 직장에서의 승진가능성에 부정적인 영향을 미칠 수 있음을 보고하였다. 또한 남성 고용주들의 경우, 동일한 조건이라 면 말을 더듬는 사람보다 말을 더듬지 않는 사람을 고용하려는 경 향이 나타났다고 하였다. 이러한 일반인의 반응은 결과적으로 말 더듬는 사람의 사회 생활에 부정적인 영향을 미칠 수 있음을 시사 한다. 또한 국외 선행연구들의 '사회적 거리/연민' 평균점수는 대부 분 중립에 가깝거나 양수를 보인데 반해(Li \& Arnold, 2015; St. Louis, 2012a, 2012b) 본 연구결과는 모든 집단의 '사회적 거리/연민' 평 균점수가 음수인 것으로 나타나 국내 일반인의 말더듬는 사람에 대한 친근감이나 이해 정도가 상대적으로 더 낮았던 것으로 나타 났다. 반면 국내에서 교사들을 대상으로 POSHA-S를 사용한 Ko (2015)는 말더듬 학생을 교육한 경험이 있는 교사집단의 사회적 거 리/연민’의 평균점수가 -23.5점으로 말더듬 학생을 교육한 경험이 없는 교사집단의 평균점수인 4.0 점에 비해 유의하게 낮았음을 보 고하였다. 따라서 이 구성요소는 지역이나 문화, 직업, 말더듬는 사 람에 대한 친숙함 정도를 감안한 후속 연구가 이루어져야 할 것으 로 보인다.

구성요소들의 점수를 통해 최종적으로 얻게 되는 '말더듬는 사 람에 대한 자기반응 점수 역시 연령과 성별에 상관 없이 음수로 나 온 것은 국내 일반인이 말더듬는 사람에 대해 보이는 자기반응이 긍정적이지 않았음을 의미한다. 하지만 단순히 이 하위범주 점수만 으로 결과를 일반화하여 설명하는 것보다는 각 구성요소의 특성 을 감안하여 말더듬는 사람에게 보이는 자기반응을 종합적으로 해 석하는 것이 더 적절할 것이다. 일반인은 말더듬는 사람과의 의사 소통 경험 혹은 그들과 대면한 경험이 적기 때문에 말더듬이라는 장애가 생소할 수 있고, 말더듬에 대한 객관적인 정보나 지식을 얻 을 수 있는 환경 또한 부족할 수 있다. 또한 비정상적인 비유창성뿐 만 아니라 이로 인한 신체적 부수행동을 보이는 말더듬는 사람과 의 의사소통이 불편하고 이로 인해 사회적 거리가 멀어질 수 있다. 하지만 이 연구결과에서는 일반인이 말더듬는 사람에게 도움을 주 고자 하는 긍정적 가능성을 함께 가지고 있었음을 알 수 있었다.

이 연구는 다양한 구성요소들을 통해 일반인이 말더듬는 사람 
에게 보이는 자기반응이 어떠한지를 수량화시켜 살필 수 있었으며, 일반인을 대상으로 한 말더듬 관련 교육의 필요성을 확인할 수 있 었다는데 임상적 의의를 갖는다. 일반인이 말더듬에 대해 보다 명 확한 지식이나 정보를 가지게 된다면 말더듬에 대한 이해가 높아질 수 있고 이를 통해 말더듬는 사람에게 보이는 행동적/정서적 반응 이 긍정적으로 변화되길 기대할 수 있기 때문이다(Abdalla \& St. Louis, 2014; Flynn \& St. Louis, 2011). 또한 장기적으로는 말더듬는 사람이 자신의 말더듬으로 인하여 겪게 되는 다양한 환경적 요인 을 감소시켜 줄 수 있을 것으로 기대한다. 후속연구를 위한 제언은 다음과 같다. 첫째, 본 연구에서는 연령과 성별에 따른 특성을 '사회 적 거리/연민'의 구성요소에서만 찾을 수 있었다. 연령과 성별뿐 아 니라 교육년수나 직업과 같이 보다 다양한 인구통계학적 변인을 독 립변수로 설정한 후속연구가 이루어진다면 말더듬는 사람에 대한 일반인의 자기반응을 보다 세밀하게 살필 수 있을 것으로 보인다. 둘째, POSHA-S의 또 다른 하위범주에 대한 연구가 필요할 것이다. 서론에서 언급하였듯이 POSHA-S에서 제시하는 또 다른 말더듬 관련 하위범주는 '말더듬는 사람에 대한 신념', 즉 고정관념이다. 본 연구처럼 다양한 인구통계학적 변인을 사용하여 이 하위범주를 연구한다면 일반인이 말더듬는 사람에 대해 어떠한 고정관념을 가 지고 있는지 보다 체계적으로 파악할 수 있을 것으로 보인다. 마지 막으로, 말더듬에 대한 정의나 말더듬는 사람에 대한 예시 제공 여 부에 따라 일반인이 보이는 자기반응을 비교할 수 있을 것으로 보 인다. 본 연구는 말더듬는 사람에 대한 특별한 정의나 예시 없이 대 상자가 일반적으로 생각하는 말더듬는 사람에 대한 자기반응을 조사하였다. 말더듬에 대한 명확한 정의나 예시가 제공된다면 대상 자의 반응을 보다 면밀하게 살필 수 있을 것으로 보인다.

\section{REFERENCES}

Abdalla, F., \& St. Louis, K. O. (2014). Modifying attitudes of Arab school teachers toward stuttering. Language, Speech, and Hearing Services in Schools, 45, $14-25$.

Al-Khaledi, M., Lincoln, M., McCabe, P., Packman, A., \& Alshatti, T. (2009). The attitudes, knowledge and beliefs of Arab parents in Kuwait about stuttering. Journal of Fluency Disorders, 34, 44-59.

Arnold, H. S., Li, J., \& Goltl, K. (2015). Beliefs of teachers versus non-teachers about people who stutter. Journal of Fluency Disorders, 43, 28-39.

Boyle, M. P., Blood, G. W., \& Blood, I. M. (2009). Effects of perceived causality on perceptions of persons who stutter. Journal of Fluency Disorders, 34, 201-218.
Chon, H., \& Yaruss, J. S. (2015). A preliminary study on the development of the Korean version of the Overall Assessment of the Speaker's Experience of Stuttering (OASES) for adults. Journal of Speech-Language \& Hearing Disorders, 24, 145-155.

Craig, A., Tran, Y., \& Craig, M. (2003). Stereotypes towards stuttering for those who have never had direct contact with people who stutter: a randomized and stratified study. Perceptual and Motor Skills, 97, 235-245.

Crowe, T. A., \& Walton, J. H. (1981). Teacher attitudes toward stuttering. Journal of Fluency Disorders, 6, 163-174.

de Britto Pereira, M. M., Rossi, J. P., \& Van Borsel, J. (2008). Public awareness and knowledge of stuttering in Rio de Janeiro. Journal of Fluency Disorders, $33,24-31$.

Doody, I., Kalinowski, J., Armson, J., \& Stuart, A. (1993). Stereotypes of stutterers and nonstutterers in three rural communities in Newfoundland. Journal of Fluency Disorders, 18, 363-373.

Dorsey, M., \& Guenther, R. K. (2000). Attitudes of professors and students toward college students who stutter. Journal of Fluency Disorders, 25, 7783.

Evans, D., Healey, E. C., Kawai, N., \& Rowland, S. (2008). Middle school students' perceptions of a peer who stutters. Journal of Fluency Disorders, 33, 203-219.

Flynn, T. W., \& St. Louis, K. O. (2011). Changing adolescent attitudes toward stuttering. Journal of Fluency Disorders, 36, 110-121.

Guitar, B. (2013). Stuttering: an integrated approach to its nature and treatment (4th ed.). Philadelphia, PA: Lippincott Williams \& Wilkins.

Han, M. (2015). Stuttering perception of elementary school children using POSHA-S (Public Opinion Survey of Human Attributes-Stuttering) (Master's thesis). Catholic University of Daegu, Daegu, Korea.

Hurst, M. I., \& Cooper, E. B. (1983). Employer attitudes toward stuttering. Journal of Fluency Disorders, 8, 1-12.

Klassen, T. R. (2002). Social distance and the negative stereotype of people who stutter. Journal of Speech-Language Pathology and Audiology, 26, 9099.

Ko, Y. (2015). Elementary schoolteachers' knowledge, perceptions and attitudes towards stuttering by the experience of teaching students who stutter (Master's thesis). Chosun University, Gwangju, Korea.

Langevin, M. (2009). The Peer Attitudes Toward Children who Stutter scale: reliability, known groups validity, and negativity of elementary school-age children's attitudes. Journal of Fluency Disorders, 34, 72-86.

Langevin, M., Kleitman, S., Packman, A., \& Onslow, M. (2009). The Peer At- 
titudes Toward Children who Stutter (PATCS) scale: an evaluation of validity, reliability and the negativity of attitudes. International Journal of Language \& Communication Disorders, 44, 352-368.

Lee, K. (2013). Perception toward stuttering by teachers in Daegu area. Communication Sciences and Disorders, 18, 447-458.

Lee, M. J., Choi, Y. J., \& Choi, S. B. (2010). Multi-cultural society and social distance for foreigners in Korean society. Journal of the Korea Association for Survey Research, 11, 63-85.

Li, J., \& Arnold, H. S. (2015). Reactions of teachers versus non-teachers toward people who stutter. Journal of Communication Disorders, 56, 8-18.

Manning, W. H. (2010). Clinical decision making in fluency disorders (3rd ed.). Clifton Park, NY: Delmar, Cengage Learning.

Özdemir, R. S., St. Louis, K. O., \& Topbaş, S. (2011). Stuttering attitudes among Turkish family generations and neighbors from representative samples. Journal of Fluency Disorders, 36, 318-333.

Schlagheck, A., Gabel, R., \& Hughes, S. (2009). A mixed methods study of stereotypes of people who stutter. Contemporary Issues in Communication Sciences and Disorders, 36, 108-117.

Sim, H. S. (2000). Study on stereotypes of the Korean male adults who stutter. Korean Journal of Communication Disorders, 5, 192-208.

St. Louis, K. O. (2005). A global project to measure public attitudes of stuttering. The ASHA Leader, 10, 12-13.

St. Louis, K. O. (2011). The public opinion survey of human attributes-stuttering (POSHA-S): summary framework and empirical comparisons. Journal of Fluency Disorders, 36, 256-261.

St. Louis, K. O. (2012a). Research and development on a public attitude instrument for stuttering. Journal of Communication Disorders, 45, 129-146.
St. Louis, K. O. (2012b). Male versus female attitudes toward stuttering. Journal of Communication Disorders, 45, 246-253.

St. Louis, K. O. (2014). International project on attitudes toward human attributes (IPATHA). Retrieved from http://www.stutteringattitudes.com/documents/SummaryDemogrTableMaster11_6_14.pdf.

St. Louis, K. O., Lubker, B. B., Yaruss, J. S., \& Aliveto, E. F. (2009). Development of a prototype questionnaire to survey public attitudes toward stuttering: reliability of the second prototype. Contemporary Issues in Communication Sciences and Disorders, 36, 101-107.

St. Louis, K. O., Reichel, I. K., Yaruss, J. S., \& Lubker, B. B. (2009). Construct and concurrent validity of a prototype questionnaire to survey public attitudes toward stuttering. Journal of Fluency Disorders, 34, 11-28.

St. Louis, K. O., Sønsterud, H., Carlo, E. J., Heitmann, R. R., \& Kvenseth, H. (2014). Public attitudes toward-and identification of - cluttering and stuttering in Norway and Puerto Rico. Journal of Fluency Disorders, 42, 21-34.

Weidner, M. E., St. Louis, K. O., Burgess, M. E., \& LeMasters, S. N. (2015). Attitudes toward stuttering of nonstuttering preschool and kindergarten children: a comparison using a standard instrument prototype. Journal of Fluency Disorders, 44, 74-87.

Wingate, M. E. (1964). A standard definition of stuttering. Journal of Speech and Hearing Disorders, 29, 484-489.

World Health Organization. (2001). International Classification of Functioning, Disability and Health (ICF). Geneva: Author.

Yaruss, J. S., \& Quesal, R. W. (2004). Stuttering and the International Classification of Functioning, Disability, and Health (ICF): an update. Journal of Communication Disorders, 37, 35-52. 


\section{국문초록}

\section{연령과 성별에 따른 일반인의 말더듬는 사람에 대한 자기반응 비교}

\section{전희정}

조선대학교 언어치료학과

배경 및 목적: 이 연구는 일반인이 말더듬는 사람에 대해 보이는 자기반응을 인구통계학적 변인인 성별과 연령 간 비교를 통해 보다 구 체적으로 살피고자 하는 데 목적이 있었다. 방법: 연구대상자는 만 19 세 이상의 성인 226명이었다. 모든 대상자는 POSHA-S의 '말더듬 는 사람에 대한 자기반응' 범주에 속하는 문항에 답하였다. 각 문항에 대한 응답은 POSHA-S의 분석방법을 따라 - 100 점에서 +100 점으 로 변환되었으며, 변환된 점수를 사용하여 ‘수용/도움, '사회적 거리/연민', '지식/경험' '지식의 출처' 구성요소 점수를 산출하였다. 또한 구성요소 점수들의 평균을 계산하여 '말더듬는 사람에 대한 자기반응' 점수를 산출하였다. 결과: '수용/도움, '지식/경험', '지식의 출처' 의 점수는 연령과 성별에 따른 유의한 차이가 나타나지 않았다. 사회적 거리/연민'점수는 남성집단에서 20 대 집단이 40 대 집단과 50 대 이상 집단보다 유의미하게 높게 나타났다. '말더듬는 사람에 대한 자기반응 하위점수는 연령과 성별에 따른 유의한 차이가 나타나지 않았다. 논의 및 결론: 일반인에게서 나타난 말더듬는 사람에 대한 자기반응은 성별과 연령에 관계없이 부정적이었다. 이는 부분적으 로 말더듬 혹은 말더듬는 사람과 관련된 '지식/경험'의 부족 때문으로 보인다. 하지만 일반인은 말더듬는 사람에게 도움을 주고자 하는 모습을 보이는 것으로 나타났다. 40 대 이상 연령대의 남성집단은 어린 연령대의 남성집단에 비해 말더듬는 사람에 대한 이해 정도나 친 근감이 낮은 것으로 나타났다. 이러한 결과는 일반인을 대상으로 한 말더듬에 대한 교육 및 인식 증가의 필요성을 시사한다.

핵심어: 자기반응, 말더듬는 사람(PWS), 말더듬, POSHA-S, 연령, 성별

이 논문은 2014학년도 조선대학교 학술연구비의 지원을 받아 연구되었음.

\section{참고문헌}

고영범(2015). 말더듬 학생 교육경험 유무에 따른 초등학교 교사의 말더듬에 대한 지식과 인식 및 태도. 조선대학교대학원 석사학위논문.

심현섭(2000). 한국 말더듬 성인에 대한 고정관념 연구. 언어청각장애연구, 5, 192-208.

이경재(2013). 대구지역 교사의 말더듬에 대한 인식. 언어청각장애연구, 18, 447-458.

이명진, 최유정, 최샛별(2010). 다문화사회와 외국인에 대한 사회적 거리. 조사연구, 11, 63-85.

전희정, 스콧 야루스(2015). 성인용 전반적 말더듬 경험 평가(OASES)의 국내적용을 위한 기초 연구: 타당도와 신뢰도를 중심으로. 언어치료연구, 24, 145-155.

한미애(2015). POSHA-S를 이용한 초등학교 고학년의 말더듬 인식. 대구카톨릭대학교대학원 석사학위논문. 